Supporting Information for:

\title{
Rapid Detection of Pseudomonas aeruginosa Biofilms via Enzymatic
}

\section{Liquefaction of Respiratory Samples}

Antonio Clemente, ${ }^{1,}{ }^{*}$ Alejandra Alba-Patiño, ${ }^{1}$ Estrella Rojo-Molinero, ${ }^{2}$ Steven M. Russell, ${ }^{1}$ Marcio Borges, ${ }^{1,3}$ Antonio Oliver, ${ }^{2}$ and Roberto de la Rica., ${ }^{1,}$

${ }^{1}$ Multidisciplinary Sepsis Group, Health Research Institute of the Balearic Islands (IdISBa).

${ }^{2}$ Servicio de Microbiología, Hospital Son Espases, Health Research Institute of the Balearic Islands (IdISBa), Palma de Mallorca, Spain.

${ }^{3}$ Multidisciplinary Sepsis Unit, ICU, Son Llàtzer University Hospital.

\section{Contents}

Video S1. Liquefaction of sputum containing P. aeruginosa by $\mathrm{H}_{2} \mathrm{O}_{2}$.

Video S2. Liquefaction of sputum containing mixed flora by $\mathrm{H}_{2} \mathrm{O}_{2}$.

Video S3. Inhibition of sputum liquefaction by $0.01 \mathrm{M} \mathrm{NaN}_{3}$.

Video S4. Inhibition of sputum liquefaction by $0.1 \mathrm{M} \mathrm{NaN}_{3}$.

Video S5. Inhibition of sputum liquefaction by $1 \mathrm{M} \mathrm{NaN}_{3}$.

Figure S1. Detection of $P$. aeruginosa with ELISA.

Figure S2. Evaluation of the impact of $\mathrm{H}_{2} \mathrm{O}_{2}$ treatment on antibody-antigen interactions.

Figure S3. Influence of incubation time with $\mathrm{H}_{2} \mathrm{O}_{2}$ on bacterial antigens release.

Figure S4. $\mathrm{H}_{2} \mathrm{O}_{2}$ effect on microstructure and cell viability of $P$. aeruginosa biofilms evaluated by CLSM.

Figure S5. Effect of Fe starvation on bubble production and cell death susceptibility.

Figure S6. Effect of $\mathrm{H}_{2} \mathrm{O}_{2}$ addition on antigen release and biomass of biofilms grown under Fe starvation conditions.

Figure S7. Ellman's reagent reduction by hydrogen peroxide and dithiotreitol.

Figure S8. Detection of P.aeruginosa with immunosensors and a scanner.

Figure S9. Liquefaction of sputum samples.

Table S1. Comparison between our immunosensor and other methods to detect $P$. aeruginosa. 


\section{S1. ELISA for P. aeruginosa}

ELISA protocol: $100 \mu \mathrm{L}$ of samples containing P. aeruginosa was added to a 96-well ELISA plates and dried by overnight incubation at $37{ }^{\circ} \mathrm{C}$ on a heating plate. Next, plates were washed 3 times with PBS containing 0.1\% Tween 20 (PBST), blocked during $2 \mathrm{~h}$ at room temperature (RT) with PBS containing $5 \mathrm{mg} \cdot \mathrm{mL}^{-1}$ bovine serum albumin (BSA) and washed again 3 times with PBST. Then, $100 \mu \mathrm{L}$ of primary anti-Pseudomonas mouse IgG monoclonal antibody (Abcam) diluted 1:600 in PBST was added and incubated for $1 \mathrm{~h}$ at RT. After washing 5 times with PBST, $100 \mu \mathrm{L}$ of secondary biotinylated anti-mouse IgG (Fc specific) produced in goat (ThermoFisher, 1:3000 in PBST) was added for $1 \mathrm{~h}$ at RT. After washing 5 times, $100 \mu \mathrm{L}$ of streptavidin-HRP diluted 1:3000 in PBST was added for $30 \mathrm{~min}$ at RT. Subsequently, the plates were washed 5 times with PBST and $100 \mu \mathrm{L}$ of $100 \mu \mathrm{g} / \mathrm{mL}$ of TMB (3,3',5,5'-Tetramethylbenzidine, Sigma) with $1.2 \mathrm{mM}$ of $\mathrm{H}_{2} \mathrm{O}_{2}$ in $50 \mathrm{mM}$ acetate buffer (pH 5.0) was added for $5 \mathrm{~min}$ at RT. Finally, the colorimetric reaction was stopped with 100 $\mu \mathrm{L}$ of $2 \mathrm{~N} \mathrm{H}_{2} \mathrm{SO}_{4}$ and absorbance was measured at $450 \mathrm{~nm}$.

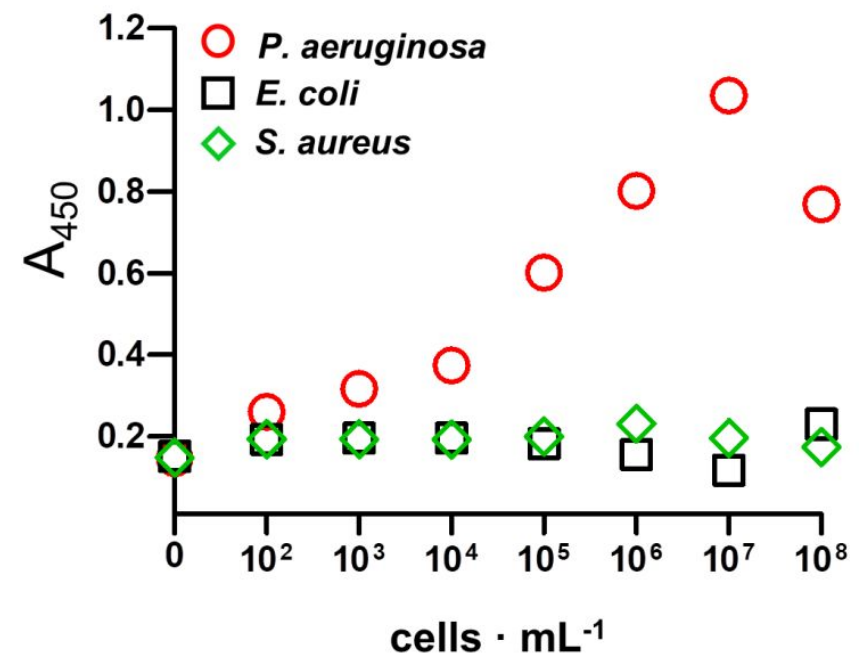

Figure S1. Detection of $P$. aeruginosa with ELISA; Absorbance with respect to the concentration of $P$. aeruginosa (red dots), E. coli (black squares) or S. aureus (green diamonds) after following the proposed ELISA protocol for P. aeruginosa detection using bacterial suspensions in PBS.

Fig. S1 shows a calibration plot using solutions containing known concentrations of $P$. aeruginosa and E. coli or S. aureus as controls. Experiments with increasing concentrations of $P$. aeruginosa show a concentration-dependent signal, whereas the signal in control 
experiments remains constant. These experiments validate the proposed ELISA for the specific detection and quantification of $P$. aeruginosa antigens.

To demonstrate that bacterial antigens are released from the plate by the $\mathrm{H}_{2} \mathrm{O}_{2}$-mediated generation of bubbles (Fig. 3D), the plates were rinsed after biofilm formation and $175 \mu \mathrm{L}$ of PBS containing $\mathrm{H}_{2} \mathrm{O}_{2}$ in the concentration range between $0.01 \mathrm{M}$ to $1 \mathrm{M}$ was added. After 1 , 3 or $5 \mathrm{~min}, 100 \mu \mathrm{L}$ of the resulting samples was collected and kept at $-20{ }^{\circ} \mathrm{C}$ until analyzed with the ELISA protocol shown above. Results are shown in Fig. 3 in the main text and in Fig. S3.

\section{S2. Impact of $\mathrm{H}_{2} \mathrm{O}_{2}$ treatment on antibody-antigen interactions.}

$100 \mu \mathrm{L}$ of solutions containing known concentrations of $P$. aeruginosa were added to a 96well ELISA plates and left to dry. After washing and blocking as detailed in Section S1, 100 $\mu \mathrm{L}$ of primary anti-Pseudomonas mouse IgG monoclonal antibody (Abcam) diluted 1:600 in PBST with increasing concentrations of hydrogen peroxide between $0.01 \mathrm{M}$ and $1 \mathrm{M}$ was added for $1 \mathrm{~h}$ at RT. Subsequent ELISA steps were performed as shown in S1.

In Fig. S2 there is a light decrease in signal when the concentration of $\mathrm{H}_{2} \mathrm{O}_{2}$ is $0.3 \mathrm{M}$ and the concentration of bacteria is $10^{6}$ cells $\cdot \mathrm{mL}^{-1}$ or higher. This decrease is more pronounced when the concentration of $\mathrm{H}_{2} \mathrm{O}_{2}$ is $1 \mathrm{M}$. These experiments show that adding an excess of $\mathrm{H}_{2} \mathrm{O}_{2}$ may impair antibody-antigen interactions in sandwich-type ELISA. 


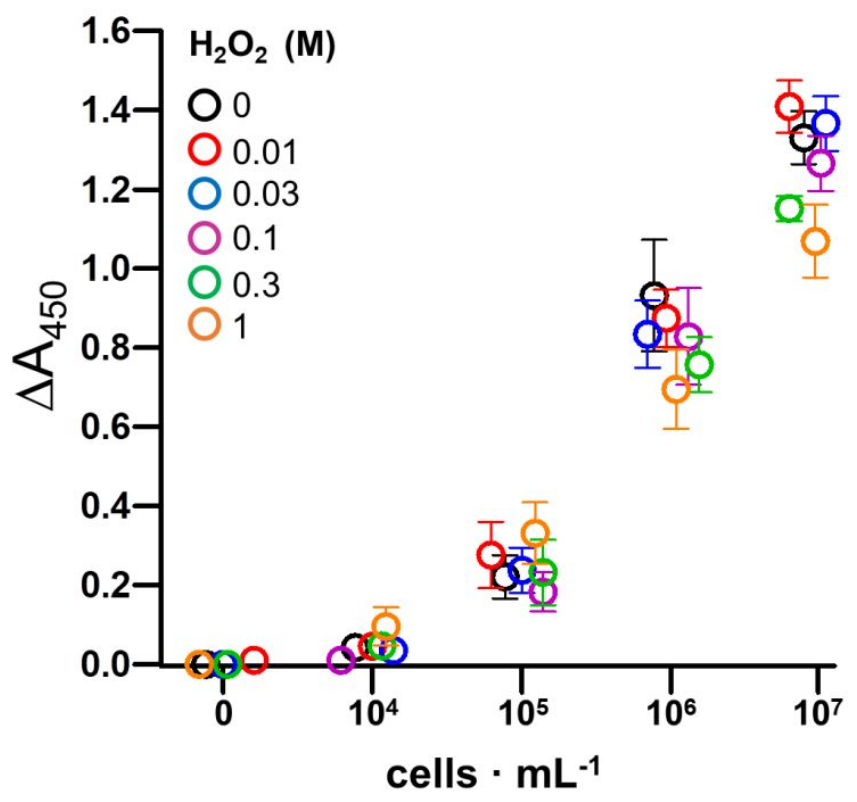

Figure S2. Evaluation of the impact of $\mathrm{H}_{2} \mathrm{O}_{2}$ treatment on antibody-antigen interactions; Absorbance with respect to the concentration of $P$. aeruginosa detected by a modified ELISA protocol in which the primary monoclonal antibody against $P$. aeruginosa is incubated in the presence of hydrogen peroxide at $0 \mathrm{M}$ (black), $0.01 \mathrm{M}$ (red), $0.03 \mathrm{M}$ (blue), $0.1 \mathrm{M}$ (purple), $0.3 \mathrm{M}$ (green) or $1 \mathrm{M}$ (orange). Error bars are the standard deviation $(\mathrm{n}=5)$. Data are expressed as the increase in absorbance $(\Delta \mathrm{A})$ with respect to the wells without bacteria for each experimental condition.

\section{S3. Impact of incubation time with $\mathrm{H}_{2} \mathrm{O}_{2}$ on antigen release from biofilms.}

Fig. S3 shows ELISA performed in the same conditions as the experiment in Fig. 3D but adding $\mathrm{H}_{2} \mathrm{O}_{2}$ for 3 or $5 \mathrm{~min}$. Increasing the incubation time with $\mathrm{H}_{2} \mathrm{O}_{2}$ increases the ELISA signal at low concentrations of peroxide. However, the signal is the same when $\mathrm{H}_{2} \mathrm{O}_{2}$ is added to a final concentration of $0.3 \mathrm{M}$ regardless of the incubation time. Since our aim is to disrupt the biofilms as rapidly as possible, and adding $0.3 \mathrm{M} \mathrm{H}_{2} \mathrm{O}_{2}$ has a small impact on antibodyinteractions (Fig. S2), an incubation time of $60 \mathrm{~s}$ with $0.3 \mathrm{M} \mathrm{H}_{2} \mathrm{O}_{2}$ was chosen as optimal for posterior experiments involving the detection of $P$. aeruginosa in respiratory samples. 

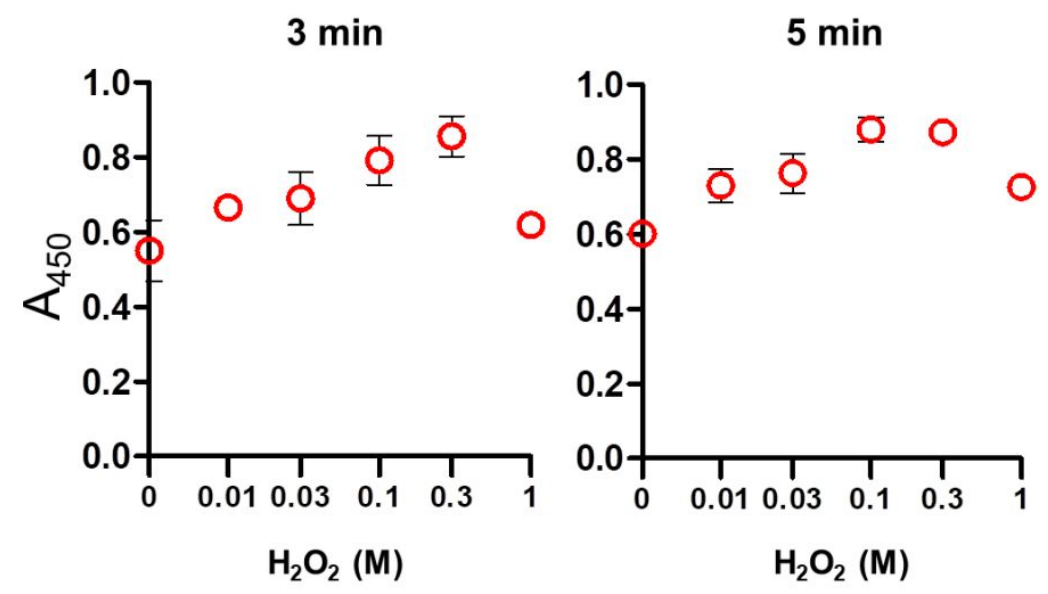

Figure S3. Influence of incubation time with $\mathrm{H}_{2} \mathrm{O}_{2}$ on bacterial antigens release; Absorbance measured after releasing bacterial antigens from biofilms using $\mathrm{H}_{2} \mathrm{O}_{2}$ at different concentrations for $3 \mathrm{~min}$ (left) or $5 \mathrm{~min}$ (right), following the proposed ELISA protocol to detect $P$. aeruginosa. Error bars are the standard deviation $(n=6)$.

\section{S4. $\mathrm{H}_{2} \mathrm{O}_{2}$ effect on microstructure and cell viability of $P$. aeruginosa biofilms evaluated by CLSM.}

We performed confocal laser scanning microscopy (CLSM) experiments to observe with higher resolution the biofilm microstructure and the integrity of the bacterial membranes after hydrogen peroxide addition (Fig. S4). After growing P. aeruginosa control biofilms or Fedeprived biofilms for 24 hours in micro-slides for CLSM observations, as detailed in the methods section of the main text and S5-S6, cells were died by a double staining procedure with SYTO9 and Propidium iodide using the FilmTracer LIVE/DEAD Biofilm Viability Kit (Invitrogen). Then, CLSM images were obtained with a LSM 710 confocal microscope (Carl Zeiss) previously and after $0.3 \mathrm{M} \mathrm{H}_{2} \mathrm{O}_{2}$ treatment by using $63 \mathrm{X}$ oil immersion objective lenses.

In Fig. S4 confocal 3D images of biofilms show the intense fluorescent signal of SYTO9 dye (green) and negligible signal of Propidium iodide (red) in biofilms grown in the absence or presence of Fe chelator (Fig. S4 (i-ii)) indicating a high density of viable cells within biomass. After addition of $0.3 \mathrm{M} \mathrm{H}_{2} \mathrm{O}_{2}$ the green signal drastically decreases in control biofilms without Fe deprivation (Fig. S4 (i-iii) but remains unaltered in those grown in the presence of Fe chelator (Fig. S4 (ii-iv). In contrast, the red signal is absent when $\mathrm{H}_{2} \mathrm{O}_{2}$ is added in both cases (Fig. S4 (iii-iv)). This experiment demonstrates that when catalase 
generates bubbles by the hydrolysis of $\mathrm{H}_{2} \mathrm{O}_{2}$ the biofilm architecture is deeply disrupted and that this disruption can be prevented if catalase activity is inhibited. Cell viability is conserved, reinforcing the idea that biofilm disruption is originated by the generation of bubbles and not by the biocide action of $\mathrm{H}_{2} \mathrm{O}_{2}$.

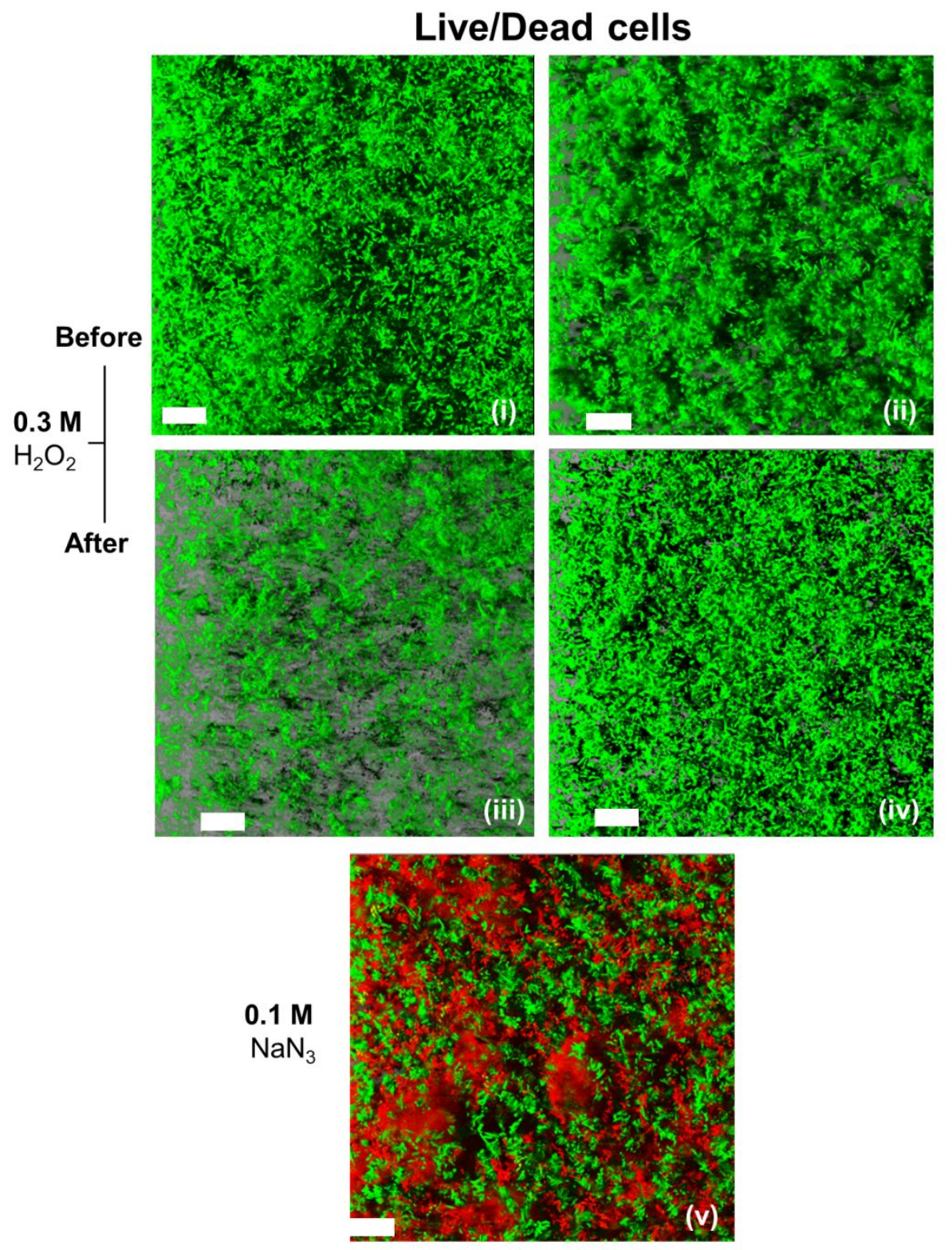

Figure S4. $P$. aeruginosa biofilm microstructure and bacterial membrane integrity after $\mathrm{H}_{2} \mathrm{O}_{2}$ treatment; 3D confocal imaging before (i-ii) and after (iii-iv) $0.3 \mathrm{M} \mathrm{H}_{2} \mathrm{O}_{2}$ treatment in control biofilms (left) and biofilms with low catalase activity grown in the presence of $0.25 \mathrm{mM} 2-2$ 'Bipyridyl as Fe chelator (right) for 24 hours. 3D confocal imaging after adding $0.1 \mathrm{M} \mathrm{NaN}_{3}$ (v) as positive control of membrane integrity loss (cell death) in a control biofilm. Green (SYTO9) and red (Propidium iodide) colours indicate the presence of live and dead cells respectively. Scale bar: $15 \mu \mathrm{m}$. 


\section{S5 and S6. Biofilms grown under Fe starvation conditions.}

When $P$. aeruginosa biofilms are grown in the presence of a chelating agent the resulting $\mathrm{Fe}$ starvation condition decreases the catalase activity of the bacteria. ${ }^{35}$ With this in mind, we designed experiments to prove that catalase activity is responsible for release of antigens shown in Fig. 3D. PAO1 strain of P. aeruginosa was inoculated into 96-well round bottom plates filled with $100 \mu \mathrm{L}$ of LB broth culture supplemented with the chelating agent 2,2'bypiridyl (Sigma) to increasing final concentrations between $0.125 \mathrm{mM}$ and $1.75 \mathrm{mM}$. Then, plates were incubated $24 \mathrm{~h}$ in a $5 \% \mathrm{CO}_{2}$ atmosphere and $37{ }^{\circ} \mathrm{C}$ until biofilms were formed. Next, we followed the protocol for in vitro disruption of $P$. aeruginosa biofilms (detailed in the methods section of the main text) and evaluated the antigen release by ELISA as explained in S1.

When biofilms were formed under Fe limitation conditions the production of bubbles after addition of $\mathrm{H}_{2} \mathrm{O}_{2}$ decreases, as shown in Fig. S5A, which shows that catalase activity is reduced. We analyzed the bacterial membrane permeability by a propidium iodide staining protocol (detailed in the methods section of the main text) in order to evaluate the extent to which catalase activity can be inhibited without increasing cell death susceptibility against hydrogen peroxide. To this end, we applied the $0.3 \mathrm{M} \mathrm{H}_{2} \mathrm{O}_{2}$ treatment for $60 \mathrm{~s}$ and then we analyzed the membrane permeability. In Fig. S5B adding $\mathrm{H}_{2} \mathrm{O}_{2}$ has no effect when the concentration of 2,2'-bypiridyl is $0.5 \mathrm{mM}$. However, at higher concentrations the cell permeability increases as the concentration of chelating agent increases because catalase activity is reduced, and therefore the cells are more susceptible to the biocide action of $\mathrm{H}_{2} \mathrm{O}_{2}$. 


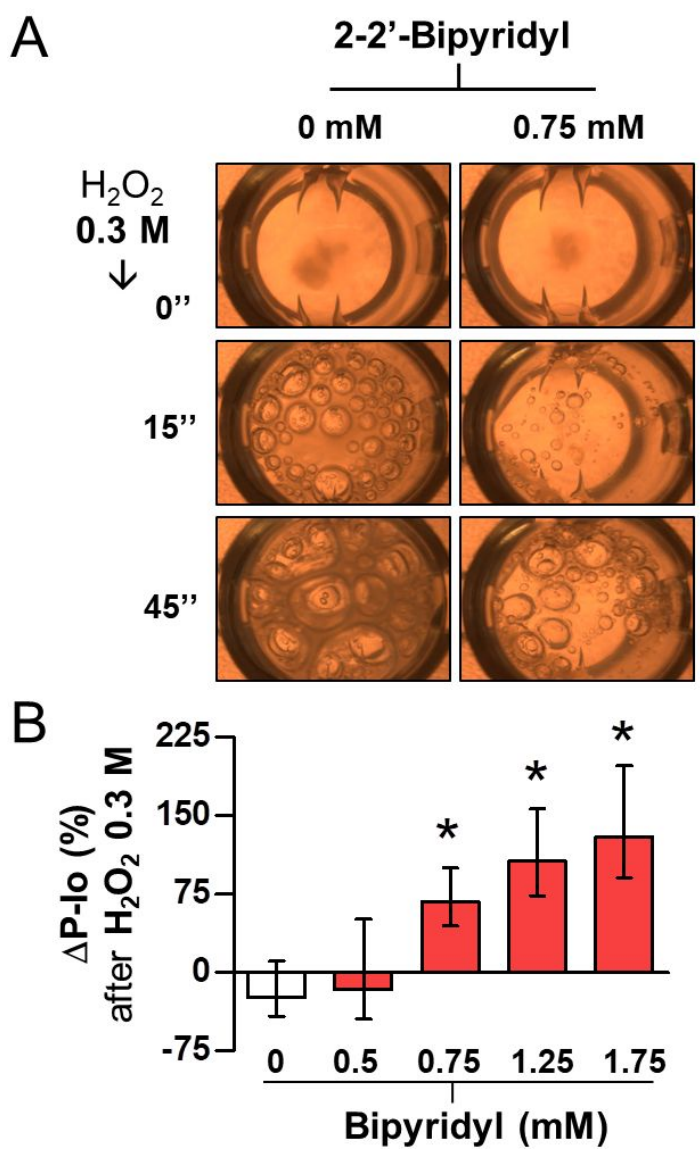

Figure S5. Effect of Fe starvation on bubble production (A) and cell death susceptibility (B). (A) Photographs of P. aeruginosa biolfims grown in the presence of the Fe chelator 2-2'Bipyridyl in a 96-well plate after adding $\mathrm{H}_{2} \mathrm{O}_{2}$ at $0.3 \mathrm{M}$ for 0,15 and $45 \mathrm{~s}$. (B) Percentage increase of propidium iodide (P-Io) fluorescence intensity (cell death) after adding $\mathrm{H}_{2} \mathrm{O}_{2}$ at $0.3 \mathrm{M}$ for $60 \mathrm{~s}$ to biofilms grown in the presence of increasing concentrations of Fe chelator. Data are expressed as medians with interquartile range $(n=24) .{ }^{*} p$-value $<0.05$ obtained with a Kruskall-wallis test.

To prove that catalase activity is responsible for releasing antigens, we quantified the concentration of antigens in supernatants after adding hydrogen peroxide to biofilms grown under optimal conditions to preserve cell survival $(<0.5 \mathrm{mM}$ chelating agent, Fig. S5B). Inhibiting catalase activity under this condition decreases the ELISA signal in Fig. S6A, which indicates that less antigens are being released from the biofilm. The following experiment was performed to demonstrate that the lower ELISA signal is originated by a reduction in antigen release and not by variations in the biomass of the biofilm induced by the Fe starvation protocol. Briefly, Fe-starved biofilms were decanted in order to remove all 
planktonic cells and flocs and washed 3 times by immersion in sterile PBS. Then, $125 \mu \mathrm{L}$ of $0.1 \%$ crystal violet was added to empty wells containing adherent biofilms and plates were incubated for $15 \mathrm{~min}$ at RT. Finally, stained biofilms were washed 3 times again and dissolved for 10 min with $200 \mu \mathrm{L}$ of $30 \%$ acetic acid prior to biomass quantification by measuring the absorbance at $590 \mathrm{~nm}$. In Fig. S6B the biomass of biofilms is not altered when the chelating agent is added at the concentration used in Fig. S6A. Since the biomass (Fig. S6B) and susceptibility to the biocide action of $\mathrm{H}_{2} \mathrm{O}_{2}$ (Fig. S5B) are not significantly altered by the Fe starvation protocol, then the decrease in ELISA in Fig. S6A can be attributed to a decrease in antigen release due to the inhibition of catalase activity in the biofilm. These experiments demonstrate that the formation of bubbles by catalase is the key factor for disrupting biofilms with the proposed method.
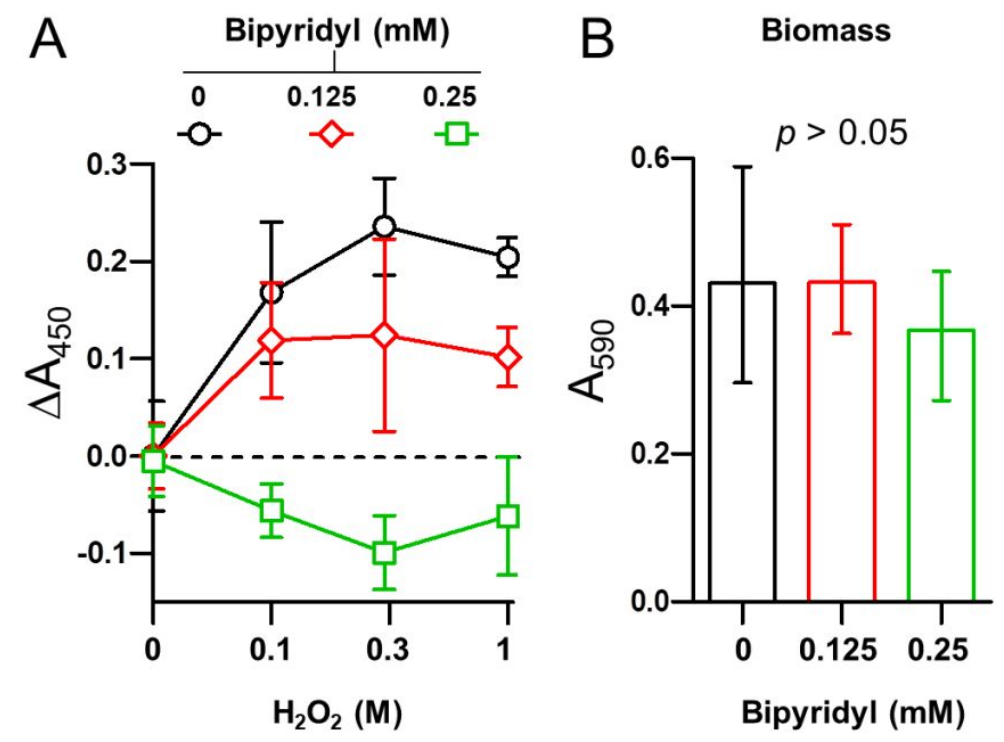

Figure S6. Effect of $\mathrm{H}_{2} \mathrm{O}_{2}$ addition on antigen release (A) and biomass (B) of biofilms grown under Fe starvation conditions (2,2 bipyridyl at $0,0.125$ and $0.25 \mathrm{mM}$ ). (A) Absorbance measured after releasing bacterial antigens from biofilms using $\mathrm{H}_{2} \mathrm{O}_{2}$ at different concentrations for $60 \mathrm{~s}$ following the proposed ELISA protocol to detect $P$. aeruginosa. Error bars are the standard deviation $(n=5)$. Data are expressed as the increase in absorbance $(\Delta A)$ at different $\mathrm{H}_{2} \mathrm{O}_{2}$ concentrations with respect to the release of bacterial antigens induced by PBS alone (no $\mathrm{H}_{2} \mathrm{O}_{2}$ ). (B) Biomass of $P$. aeruginosa biofilms grown without Fe chelator (black) or under low Fe starvation conditions (green and red). Data are expressed as medians with interquartile range $(\mathrm{n}=30)$. $P$-value was obtained with a Kruskall-wallis test. 


\section{S7. Hydrogen peroxide reduction of disulfide bonds.}

Sputasol (dithiotreitol $6.5 \mathrm{mM}$ ) acts as a liquefying agent for sputum samples by reducing disulfide bonds within mucin. We performed an Ellman's test in order to evaluate the reducing properties of hydrogen peroxide under the experimental conditions proposed for our alternative sputum liquefaction protocol. Briefly, $20 \mu \mathrm{L}$ of $4 \mathrm{mg} \cdot \mathrm{mL}^{-1}$ Ellman's reagent (5,5'-dithiobis-(2-nitrobenzoic acid) or DTNB from Sigma) in Ellman's buffer $(0.1 \mathrm{M}$ phosphate supplemented with $1 \mathrm{mM}$ EDTA, $\mathrm{pH}$ 7.4) was added to $100 \mu \mathrm{L}$ of Ellman's buffer with $0.3 \mathrm{M}$ hydrogen peroxide or $0.3 \mathrm{mM}$ dithiotreitol (Sputasol from Oxoid) in a 96-well ELISA plate. The reduction of disulfide bonds within DTNB produces a measurable colorimetric reaction. After 15 min of incubation at RT $80 \mu \mathrm{L}$ of Ellman's buffer was added to wells and the yellow-colored product was measured at $412 \mathrm{~nm}$, following the instructions provided by the manufacturer.

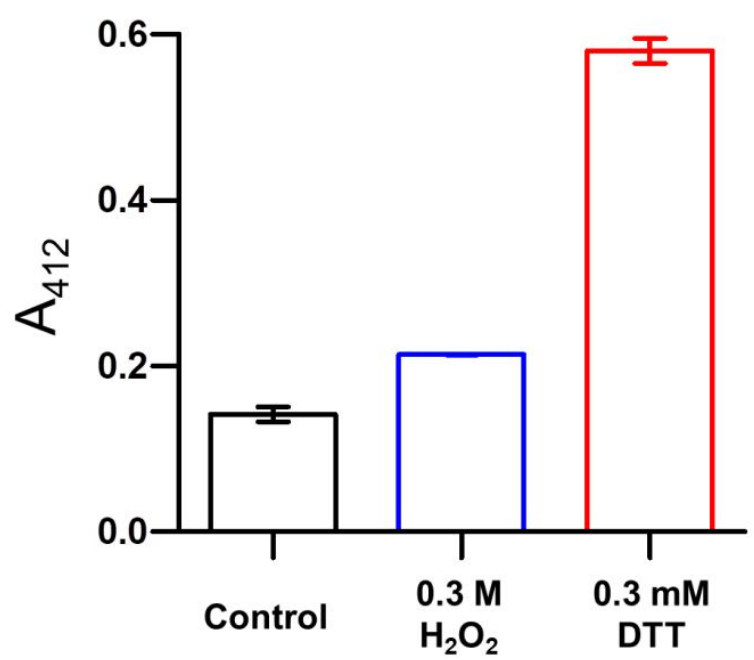

Figure S7. Ellman's reagent reduction by hydrogen peroxide and dithiotreitol. Plot representing the absorbance after adding Ellman's reagent to control buffer (black), $0.3 \mathrm{M}$ $\mathrm{H}_{2} \mathrm{O}_{2}$ (blue) and $0.3 \mathrm{mM}$ dithiotreitol (DTT, red). Error bars are the standard deviation $(\mathrm{n}=$ $3)$.

In Fig. S7 the addition of $0.3 \mathrm{M} \mathrm{H}_{2} \mathrm{O}_{2}$ has little effect compared to the experiment performed in the presence of $0.3 \mathrm{mM}$ DTT. It should be noted that $0.3 \mathrm{mM}$ DTT is 20 times less 
concentrated than Sputasol; this dilution was necessary in order to obtain a quantifiable signal with the Ellman test. These experiments demonstrate that $0.3 \mathrm{M} \mathrm{H}_{2} \mathrm{O}_{2}$ has negligible reducing power compared to $6.5 \mathrm{mM}$ DTT, which is the standard procedure for liquefying sputum samples. Therefore, these results demonstrate that the main factor for the rapid liquefaction of respiratory samples with the proposed method is the generation of bubbles by the enzyme catalase and not the reduction of disulfide bonds by $\mathrm{H}_{2} \mathrm{O}_{2}$

\section{S8. Detection of $P$. aeruginosa with immunosensors and a scanner}

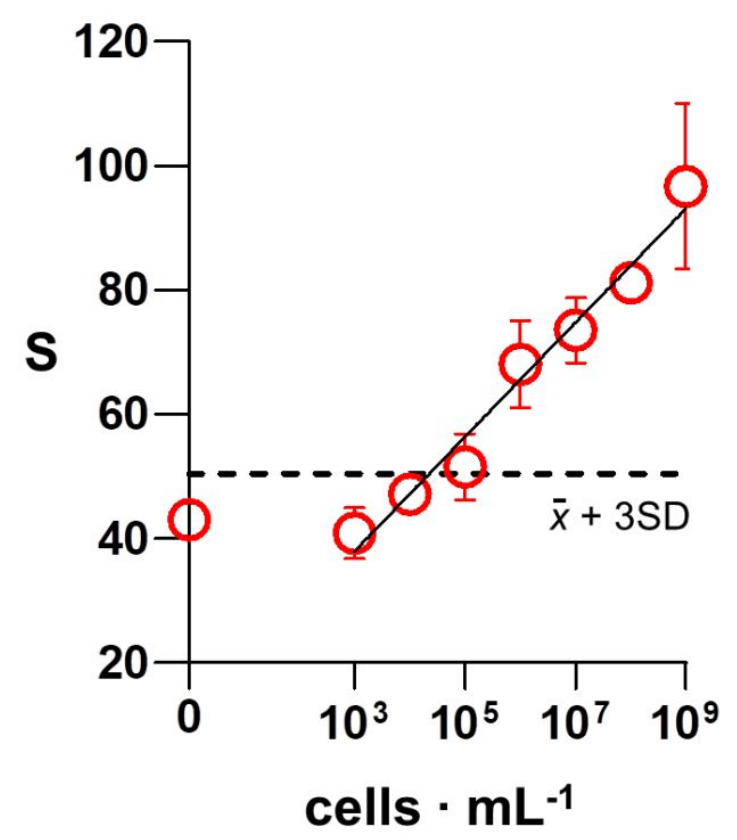

Figure S8. Detection of $P$. aeruginosa with immunosensors and a scanner instead of with the mobile app; Calibration plot representing the colorimetric signal $\mathrm{S}$ with respect to the concentration of $P$. aeruginosa (red dots) measured by scanning the paper biosensor with a desktop scanner and quantifying the pixel intensity in grayscale in a circular area within the area of interest with the histogram function of ImageJ. The dotted line shows the signal above 3 times the standard deviation of the blank. Error bars are the standard deviation $(n=3)$. 


\section{S9. Representative images of sputum samples liquefied with $0.3 \mathrm{M} \mathrm{H}_{2} \mathrm{O}_{2}$ for $60 \mathrm{~s}$.}

Images shown in Fig. S9 show sputum samples after the liquefaction procedure. As shown in Fig. 2 in the main manuscript, sputum samples infected by $P$. aeruginosa are almost completely dissolved, whereas those containing a mixed flora show different degrees of liquefaction and negative samples are almost intact. These results agree well with the idea that the presence of catalase-producing cells in respiratory samples is the key factor for liquefying samples after the addition of hydrogen peroxide.

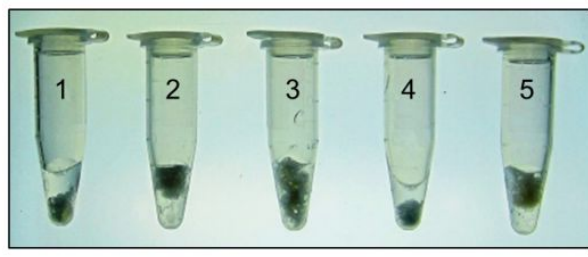

Negative
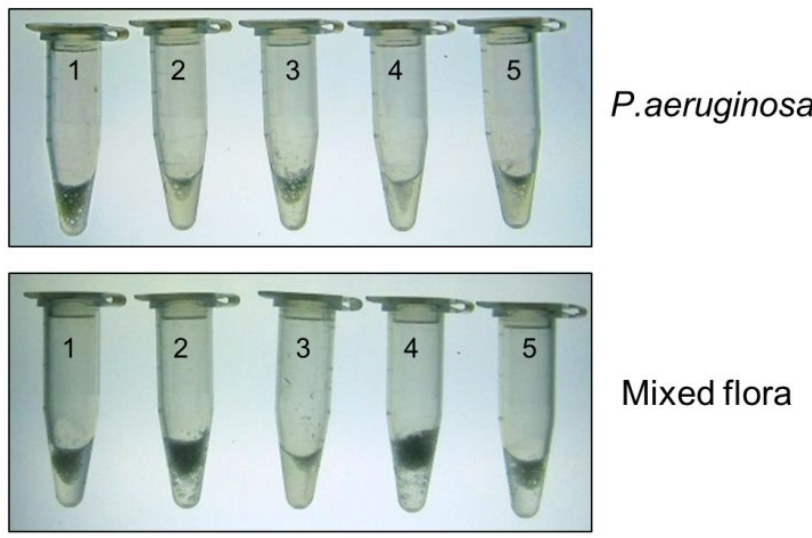

Figure S9. Liquefaction of sputum samples. Photographs of sputum samples (10 mg) negative for bacterial infection (upper row) and containing $P$. aeruginosa (middle row) or a mixed flora (lower row), after the addition of $0.3 \mathrm{M} \mathrm{H}_{2} \mathrm{O}_{2}$ for $60 \mathrm{~s}$. 
Table S1. Comparison between our immunosensor and other methods to detect $P$. aeruginosa.

\begin{tabular}{|c|c|c|c|c|c|c|c|}
\hline & Target & $\begin{array}{l}\text { Detection } \\
\text { Principle }\end{array}$ & LOD & Dynamic Range & Sample & Time & $\begin{array}{l}\text { Culture } \\
\text { required }\end{array}$ \\
\hline Alhogail et al ${ }^{1}$ & Protease & Colorimetric & $10^{2}$ cells $/ \mathrm{mL}$ & NP & Sputum & $1 \mathrm{~min}$ & Yes \\
\hline Thet et $\mathrm{al}^{2}$ & Toxins & Fluorescence & $\begin{array}{c}10^{7}-10^{8} \\
\text { cells/swab }\end{array}$ & $\begin{array}{c}10^{7}-10^{8} \\
\text { cells/swab }\end{array}$ & Wound & $2 \mathrm{~h}$ & No \\
\hline Ciui et $\mathrm{al}^{3}$ & Virulence factors & Electrochemical & NP & NP & Surfaces & $4 \mathrm{~min}$ & No \\
\hline Bai et $\mathrm{al}^{4}$ & Cells & Near-field sensing & NP & $\begin{array}{l}0.5-1 \times 10^{4} \\
\text { cells } / \mathrm{mL}\end{array}$ & Medium & $5 \mathrm{~min}$ & NP \\
\hline Liu et $\mathrm{al}^{5}$ & Nucleic acid & Colorimetric & $10^{1} \mathrm{cfu}$ & $0-10 \mathrm{cfu}$ & water & $70 \mathrm{~min}$ & No \\
\hline Ferreira e Silva ${ }^{6}$ & Pyocyanin & Electrochemical & $50-10^{3} \mathrm{nM}$ & $10 \mathrm{nM}$ & Saliva, water, surfaces & $10 \min$ & No \\
\hline Sheybani $^{7}$ & Cells & Electrochemical & $10^{2} \mathrm{cfu} / \mathrm{mL}$ & $10^{2}-10^{6} \mathrm{cfu} / \mathrm{mL}$ & Wound & $5 \mathrm{~min}$ & Yes \\
\hline Liu et $\mathrm{al}^{8}$ & Cells & Electrochemical & $10^{2} \mathrm{cfu} / \mathrm{mL}$ & $10^{2}-10^{6} \mathrm{cfu} / \mathrm{mL}$ & Tris-HCl buffer & $30 \mathrm{~min}$ & No \\
\hline Chen et $\mathrm{al}^{9}$ & Nucleic acid & Colorimetric & $20 \mathrm{cfu} / \mathrm{mL}$ & $\mathrm{NP}$ & Water, soil & $50 \mathrm{~min}$ & Yes \\
\hline Krithiga et al ${ }^{10}$ & Cells & Electrochemical & $9 \times 10^{2} \mathrm{cfu} / \mathrm{mL}$ & $10^{1}-10^{7} \mathrm{cfu} / \mathrm{mL}$ & buffer & $45 \min$ & No \\
\hline Alatraktchi et al ${ }^{11}$ & Pyocyanin & Electrochemical & $172 \mathrm{nM}$ & NP & $\begin{array}{l}\text { saline, endolaryngeal } \\
\text { suctions }\end{array}$ & $1 \mathrm{~min}$ & No \\
\hline Mukama et al'12 & Nucleic acid & Colorimetric & $1 \mathrm{cfu} / \mathrm{mL}$ & $\mathrm{NP}$ & Milk, serum, sputum & $50-80 \mathrm{~min}$ & No \\
\hline Elkhawaga et al ${ }^{13}$ & Pyocyanin & Electrochemical & $500 \mathrm{nM}$ & $1.9-238 \mu \mathrm{M}$ & culture & NP & Yes \\
\hline Maldonado et $\mathrm{al}^{14}$ & cells & BiMW & $49 \mathrm{cfu} / \mathrm{mL}$ & $8 \times 10^{2}-10^{7} \mathrm{cfu} / \mathrm{mL}$ & PBST & $12 \mathrm{~m}$ & No \\
\hline Ji et $\mathrm{al}^{15}$ & Nucleic acid & SH-SAW & $0.28 \mathrm{nM}$ & $0.1-10^{3} \mathrm{nM}$ & NP & NP & No \\
\hline Zhao et $\mathrm{al}^{16}$ & Nucleic acid & Colorimetric & $10 \mathrm{fg}$ & $\mathrm{NP}$ & sputum & $40 \mathrm{~min}$ & No \\
\hline Zhou et al ${ }^{17}$ & Nucleic acid & Electrochemical & $10 \mathrm{cfu} / \mathrm{mL}$ & $10^{1}-10^{8} \mathrm{cfu} / \mathrm{mL}$ & Simulated sputum & $375 \min$ & No \\
\hline Das et $a^{18}$ & Cells & Electrochemical & $60 \mathrm{cfu} / \mathrm{mL}$ & $\begin{array}{c}6 \times 10^{1}-6 \times 10^{7} \\
\mathrm{cfu} / \mathrm{mL}\end{array}$ & water & $10 \min$ & No \\
\hline Peng et $\mathrm{al}^{19}$ & Cells & Colorimetric & 100 cells & $\mathrm{NP}$ & Water, serum & $60 \mathrm{~min}$ & No \\
\hline This work & Cells & Colorimetric & $10^{5}$ cells $/ \mathrm{mL}$ & $10^{4}-10^{9}$ cells $/ \mathrm{mL}$ & sputum & $8 \mathrm{~min}$ & No \\
\hline
\end{tabular}

NP: not provided, "Culture" refers whether bacteriological culture was necessary prior to or during the detection. 


\section{References from Table S1}

(1) Alhogail, S.; Suaifan, G. A. R. Y.; Bikker, F. J.; Kaman, W. E.; Weber, K.; CiallaMay, D.; Popp, J.; Zourob, M. M. Rapid Colorimetric Detection of Pseudomonas Aeruginosa in Clinical Isolates Using a Magnetic Nanoparticle Biosensor. ACS Omega 2019, 4 (26), 21684-21688. https://doi.org/10.1021/acsomega.9b02080.

(2) Thet, N. T.; Mercer-Chalmers, J. D.; Greenwood, R.; Young, A.; Coy, K.; Booth, S.; Sack, A.; Jenkins, A. T. A. The SPaCE Swab: Point of Care Sensor for Simple and Rapid Detection of Acute Wound Infection. ACS Sensors 2020. https://doi.org/10.1021/acssensors.0c01265.

(3) Ciui, B.; Tertiş, M.; Cernat, A.; Săndulescu, R.; Wang, J.; Cristea, C. Finger-Based Printed Sensors Integrated on a Glove for On-Site Screening of Pseudomonas Aeruginosa Virulence Factors. Anal. Chem. 2018, 90 (12), 7761-7768. https://doi.org/10.1021/acs.analchem.8b01915.

(4) Bai, Z.; Liu, Y.; Kong, R.; Nie, T.; Sun, Y.; Li, H.; Sun, T.; Pandey, C.; Wang, Y.; Zhang, H.; et al. Near-Field Terahertz Sensing of HeLa Cells and Pseudomonas Based on Monolithic Integrated Metamaterials with a Spintronic Terahertz Emitter. ACS Appl. Mater. Interfaces 2020, 12, 35895-35902. https://doi.org/10.1021/acsami.0c08543.

(5) Liu, D.; Zhu, Y.; Li, N.; Lu, Y.; Cheng, J.; Xu, Y. A Portable Microfluidic Analyzer for Integrated Bacterial Detection Using Visible Loop-Mediated Amplification. Sensors Actuators, B Chem. 2020, 310 (February), 127834. https://doi.org/10.1016/j.snb.2020.127834.

(6) Ferreira e Silva, R.; Longo Cesar Paixão, T. R.; Der Torossian Torres, M.; de Araujo, W. R. Simple and Inexpensive Electrochemical Paper-Based Analytical Device for Sensitive Detection of Pseudomonas Aeruginosa. Sensors Actuators, B Chem. 2020, 308 (October 2019), 127669. https://doi.org/10.1016/j.snb.2020.127669.

(7) Sheybani, R.; Shukla, A. Highly Sensitive Label-Free Dual Sensor Array for Rapid Detection of Wound Bacteria. Biosens. Bioelectron. 2017, 92 (July 2016), 425-433. https://doi.org/10.1016/j.bios.2016.10.084.

(8) Liu, X.; Marrakchi, M.; Xu, D.; Dong, H.; Andreescu, S. Biosensors Based on Modularly Designed Synthetic Peptides for Recognition, Detection and Live/Dead Differentiation of Pathogenic Bacteria. Biosens. Bioelectron. 2016, 80, 9-16. https://doi.org/10.1016/j.bios.2016.01.041.

(9) Chen, Y.; Cheng, N.; Xu, Y.; Huang, K.; Luo, Y.; Xu, W. Point-of-Care and Visual 
Detection of P. Aeruginosa and Its Toxin Genes by Multiple LAMP and Lateral Flow Nucleic Acid Biosensor. Biosens. Bioelectron. 2016, 81, 317-323.

https://doi.org/10.1016/j.bios.2016.03.006.

(10) Krithiga, N.; Viswanath, K. B.; Vasantha, V. S.; Jayachitra, A. Specific and Selective Electrochemical Immunoassay for Pseudomonas Aeruginosa Based on Pectin-Gold Nano Composite. Biosens. Bioelectron. 2016, 79, 121-129.

https://doi.org/10.1016/j.bios.2015.12.006.

(11) Alatraktchi, F. A. Z. a.; Dimaki, M.; Støvring, N.; Johansen, H. K.; Molin, S.; Svendsen, W. E. Nanograss Sensor for Selective Detection of Pseudomonas Aeruginosa by Pyocyanin Identification in Airway Samples. Anal. Biochem. 2020, 593 (January), 113586. https://doi.org/10.1016/j.ab.2020.113586.

(12) Mukama, O.; Wu, J.; Li, Z.; Liang, Q.; Yi, Z.; Lu, X.; Liu, Y.; Liu, Y.; Hussain, M.; Makafe, G. G.; et al. An Ultrasensitive and Specific Point-of-Care CRISPR/Cas12 Based Lateral Flow Biosensor for the Rapid Detection of Nucleic Acids. Biosens. Bioelectron. 2020, 159 (November 2019), 112143. https://doi.org/10.1016/j.bios.2020.112143.

(13) Elkhawaga, A. A.; Khalifa, M. M.; El-Badawy, O.; Hassan, M. A.; El-Said, W. A. Rapid and Highly Sensitive Detection of Pyocyanin Biomarker in Different Pseudomonas Aeruginosa Infections Using Gold Nanoparticles Modified Sensor. PLoS One 2019, 14 (7), 1-16. https://doi.org/10.1371/journal.pone.0216438.

(14) Maldonado, J.; Estévez, M. C.; Fernández-Gavela, A.; González-López, J. J.; González-Guerrero, A. B.; Lechuga, L. M. Label-Free Detection of Nosocomial Bacteria Using a Nanophotonic Interferometric Biosensor. Analyst 2020, 145 (2), $497-$ 506. https://doi.org/10.1039/c9an01485c.

(15) Ji, J.; Yang, C.; Zhang, F.; Shang, Z.; Xu, Y.; Chen, Y.; Chen, M.; Mu, X. A High Sensitive SH-SAW Biosensor Based $36^{\circ}$ Y-X Black LiTaO3 for Label-Free Detection of Pseudomonas Aeruginosa. Sensors Actuators, B Chem. 2019, 281 (October 2018), 757-764. https://doi.org/10.1016/j.snb.2018.10.128.

(16) Zhao, F.; Niu, L.; Nong, J.; Wang, C.; Wang, J.; Liu, Y.; Gao, N.; Zhu, X.; Wu, L.; $\mathrm{Hu}, \mathrm{S}$. Rapid and Sensitive Detection of Pseudomonas Aeruginosa Using Multiple Cross Displacement Amplification and Gold Nanoparticle-Based Lateral Flow Biosensor Visualization. FEMS Microbiol. Lett. 2018, 365 (14), 1-6. https://doi.org/10.1093/femsle/fny147.

(17) Zhou, H.; Duan, S.; Huang, J.; He, F. An Ultrasensitive Electrochemical Biosensor 
ForPseudomonas Aeruginosaassay Based on a Rolling Circle Amplification-Assisted Multipedal DNA Walker. Chem. Commun. 2020, 56 (46), 6273-6276.

https://doi.org/10.1039/d0cc01619e.

(18) Das, R.; Dhiman, A.; Kapil, A.; Bansal, V.; Sharma, T. K. Aptamer-Mediated Colorimetric and Electrochemical Detection of Pseudomonas Aeruginosa Utilizing Peroxidase-Mimic Activity of Gold NanoZyme. Anal. Bioanal. Chem. 2019, 411 (6), 1229-1238. https://doi.org/10.1007/s00216-018-1555-z.

(19) Peng, H.; Chen, I. A. Rapid Colorimetric Detection of Bacterial Species through the Capture of Gold Nanoparticles by Chimeric Phages. ACS Nano 2019, 13 (2), 12441252. https://doi.org/10.1021/acsnano.8b06395. 